\title{
Workforce trends, issues and values ${ }^{1}$
}

\author{
Joanne Gard Marshall \\ University of North Carolina at Chapel Hill, Chapel Hill, NC, USA \\ E-mail:marshall@ils.unc.edu
}

\begin{abstract}
As we consider the future of the information professions, it is useful to reflect on issues related to the library and information science workforce and the values that underlie the field. The author's professional experience and research are used to highlight important practice trends such as digital libraries, embedded librarianship, broadening the audience for library and information services, involvement in problem-based learning, evidence based practice, end user searching of online databases, and the increasing need to conduct studies that link information services to key outcomes. The importance of tracking practice trends as part of the ongoing curriculum revision process is emphasized. Linking both education and research to practice will be crucial to the success of future educational programs and the ability of graduates to make a useful contribution in the workplace. Workforce tracking of alumni is a key component of effective strategic planning and overall workforce planning, especially in a time of major demographic change. Professional associations have an important role of play in continuing education and building the core ethics and values of the field.
\end{abstract}

Keywords: Trends, practice, research, linking research to practice, evidence based practice, workforce tracking, demographic change, professional associations, ethics, values

\section{Some initial thoughts}

This paper is a reflection based on my 16 years of experience as a librarian (primarily in health sciences libraries) as well as over two decades as a library and information science faculty member and administrator at the University of Toronto and the University of North Carolina at Chapel Hill. I have tried to pull out some lessons from these experiences that may be relevant to our discussions at IP2050. The past and the present can teach us a lot about change and point us in useful directions for the future.

\section{Trends based on professional experience}

My own career as a health sciences librarian was marked by many change in information and library science practice. Starting in the 1960s, the health field was one of the first to develop a large scale bibliographic database (MEDLINE). By 2000, the original bibliographic database with abstracts had morphed into full text (PubMed/MEDLINE) and health sciences library collections became increasingly available in electronic form. As a result, health sciences libraries were early adopters of the digital library concept. Many are now on their way to becoming completely digital.

There were also many changes in the nature of health library services. At McMaster University Medical Center Library where I worked for 12 years, we developed a clinical librarian program with librarians participating as members of the patient care team to provide information services for both providers and

\footnotetext{
${ }^{1}$ This work is licensed under the Creative Commons Attribution-Noncommercial No Derivations Works 3.0 Unported license. You are free to Share this work (copy, Distribute and transmit) under the following conditions: attribution, noncommercial and no derivative works. To view a copy of this license, visit http://creativecommons.org/licenses/by-nc-sa/3.0/.
} 
consumers of health care. Librarians were getting out of the library and providing information services at the point of care. We also expanded our services beyond physicians to all health professionals as well as to patients and families and caregivers. These activities also led to a partnership with our local public library. Since that time we have seen the development of what has become known as consumer health information services. Consumers are now the largest group of users of the National Library of Medicine databases and health information is one of the most frequent topics searched on the web. These specific examples are playing out in many settings. There are more and more specialized services being offered in the user's electronic workspace, expansion of services to more diverse groups and the development of new areas of information practice.

Returning once more to the health information services example, problem-based medical curricula have provided greater instructional opportunities for librarians. While intermediary searching has declined in favor or large scale end user access, the expertise of library and information professionals in database selection and search methods continues to be an important part of providing instruction and support for online access. At McMaster, the health librarians participated in a series of tutorials on "Critical Appraisal of the Literature" organized by the Department of Clinical Epidemiology and Biostatistics. These tutorials became the basis for what evolved into "evidence-based medicine". The concept of evidence-based practice has since spread to all of the health professions and beyond. Here we can see an example of the expanding educational and instructional role of library and information professionals and the increasing centrality of information or evidence as a basis for decision making in organizations.

My involvement in these activities also stimulated my interest in doing research. After all, shouldn't librarians be evidence-based in their practice too? This led to a randomized controlled trial of the clinical librarian program [6] as well as a study on the value and impact of the hospital librarian that was among the first to link the information services of librarians to patient care outcomes [7]. This is just one of many examples of how library and information professionals are moving into research roles and how research is being used to both measure value and continually improve information services.

My point in reviewing this historical background is to illustrate that some of the trends that we see today, namely digital libraries, broadening the audience for library and information services, outreach and partnerships, increasing involvement in instruction, and evidence-based practice have been percolating for some time in the world of library and information practice. While this example comes from the health sciences, I have observed similar changing in other fields. I expect that all of these trends will continue to develop and provide opportunities for information professionals in the future. As educators we need to follow practice trends and make sure that they are represented in our curriculum. We also need to build our contacts with practitioners so that we can involve them in teaching, field experience and research activities. Community-based collaborative research [4], which has been used extensively in the health field, offers a framework for practitioner/researcher partnerships that can help to make our research more relevant and useful to information and library science practitioners.

\section{Value and impact issues}

For many years libraries and other cultural institutions were supported on the basis that they were a necessary part of every community. As resources have continued to shrink, all publicly-funded institutions, including cultural and educational institutions, are being challenged to demonstrate their value to their own users and to the broader communities that they serve. This has major implications for the education of information professionals as well as for practitioners. 
Our graduates need to develop robust methodologies and systems to evaluate their products and services, not only to demonstrate value but also to improve performance. A good example of such a system if the LibQual+ program developed by the Association of Research Libraries (ARL) [1] and the resources for outcomes-based evaluation provided by Institute of Museum and Library Services (IMLS) [3]. The program evaluation model recommended by IMLS provides a framework for measuring impacts in the short term, mid-term and long term.

I am currently leading a large scale study funded by the National Library of Medicine to measure the "Value of Library and Information Services in Patient Care" [2,9]. The new study, which replicates the 1992 outcomes study that I mentioned earlier, involves 56 library sites serving 118 hospitals in the U.S. and Canada. The physicians, resident and nurses in the participating institutions were asked to recall an incident in the last three months where they had searched for information related to patient care using library resources and services. The health professionals were asked to respond to a web-based survey based on this incident. Over 16,000 critical incidents were gathered and changes as a result of using the information were reported in: advice given to patients, diagnosis, choice of drugs and other treatments, and choice of tests. Perhaps even more important, a number of serious adverse events were avoided.

The lessons that I have learned from my research are many. First, I have learned how important it is for practitioners and researchers to work together to design meaningful research that is actionable and which addresses the most critical challenges facing the profession. The community-based collaborative research approach mentioned earlier [4] can be used to accomplish this goal. In the future, we also need to develop more large scale, replicable studies that will provide opportunities for practitioners to participate in and benefit from research efforts in the field. Such studies will also provide opportunities for doctoral students to do secondary analysis of existing datasets, an approach that is common in sociology and many other social sciences.

I would like to see research, evaluation and evidence-based practice fully integrated into information and library science degree programs so the graduates are at ease with not only using research evidence but also with conducting their own studies when necessary. I would also like to see faculty engage as fully as possible with the practitioner community in teaching, research and service. In other words, I would like our future to emphasize linking research to practice.

\section{Workforce tracking issues}

Since 2005, I have led a series of research projects funded by the Institute of Museum and Library Services (IMLS) entitled Workforce Issues in Library and Information Science (WILIS). The WILIS1 project was an in-depth career study of graduates of library and information science master's programs in North Carolina from 1964 to 2007 [10].

A follow up project known as WILIS2 adapted the recent graduates' portion of the WILIS1 webbased survey so that it could be used by other information and library science programs across North America to track their alumni and evaluate the effectiveness of their degree programs. Some 39 programs participated in the WILIS2 alumni tracking study [8]. We are currently working on WILIS3 which will archive all the WILIS data for future use and provide a guide for information and library science researchers who want to make their research data more widely available.

My increased contact with IMLS during this period has made me realize what an important role this federal institute plays in supporting and developing the information and library science workforce and in 
shaping policies that guide the activities of cultural institutions of all types [5]. The WILIS projects have also increased my awareness of our need for ongoing data collection about our workforce, particularly as it morphs and changes in response to the changing landscape of information work. Unlike other professions, most notably the health sciences, information and library science is not a licensed profession. As a result, we have never been required by licensing bodies to track our workforce in a systematic way. The extent to which individual programs are able to track their alumni varies greatly, even though evaluating the impact of the degree on graduates is included in the American Library Association standards for accreditation.

In a survey of deans, directors and chairs of LIS programs we found that few programs have the resources to track the careers of their alumni on a regular basis even though they agree that it would contribute to strategic planning. IMLS has identified the LIS workforce as a priority issue for research funding and the Laura Bush Librarians for the 21st Century project has done much to provide scholarships and other forms of support for students, in particular minority students. IMLS also requires that all its funded projects address the issue of diversity. As the baby boomers retire, we will have to turn our attention even more to both recruitment and retention so that we can attract the best and the brightest into the field and keep them there once they have graduated. Those who are interested in exploring workforce issues further will find additional papers on WILIS and other studies in the Fall 2009 [11] and Fall 2010 [12] issues of the journal Library Trends.

\section{The role of professional associations}

Again drawing on my own experience, I have also been active in professional associations such as the Medical Library Association and the Special Libraries Association, helping to develop competency statements as well as educational and research policies. The latter experience has made me realize what an important role the professional associations play in supporting the lifelong learning of information professionals.

I was attending the Medical Library Association annual meeting in Seattle as I was finishing off this paper and I was struck be the vibrancy of the attendees' discussions and the sense of urgency they had about the need to change and move ahead into the digital future. At association meetings one can also see very clearly the aging of the workforce and the reduced number of younger practitioners who are ready to take on what lies ahead.

One potent example of the major changes that are happening to health sciences libraries related to the move to electronic health records (EHR). As one young librarian told me, this will be another game changer for hospital libraries. Information resources can be built into these systems for both health care providers and consumers. So what will the role of the librarian be? The National Library of Medicine reported on new standards that are being developed for these embedded EHR information systems and the need for librarians who can act as trusted experts and evaluators of the choices available to health care institutions. So one door closes and another opens. Other kinds of game changing scenarios will likely unfold in all branches of the profession as we move forward.

\section{The importance of professional values}

One of the most important roles of professional associations is to continue to build and sustain the set of values that have characterized the field of librarianship since it was established. Librarians see 
themselves as having an important social mission to preserve recorded knowledge and to provide access to information for all. Dedication to this mission gives their work personal and social meaning and has led the profession to have one of the highest job satisfaction rates of any field.

An appreciation of professional values and ethics is something that educators should support and transfer over to new entrants to the expanding field of library and information science. The values and ethics that drive our field are what set us apart and make us so important in a world where information is increasingly being seen as a commodity. Courses in ethics are becoming more common in information and library science programs and student chapters of professional associations are alive and well in many programs. I hope that we will continue to emphasize the integration of values and ethics into our curricula in the future.

\section{References}

[1] Association of Research Libraries, LibQual+, available at: http://www.libqual.org/home.

[2] K. Dunn et al., Measuring the value and impact of health sciences libraries: Planning an update and replication of the Rochester study, J. Med. Libr. Assoc. 97(4) (2009), 308-311.

[3] Institute of Museum and Library Services, Grant applications: Outcomes based evaluation, available at: http://www. imls.gov/applicants/basics.aspx.

[4] B.A. Israel et al., Methods in Community-Based Participatory Research for Health, Jossey-Bass, San Francisco, CA, 2005.

[5] C.A. Manjarrez, J. Ray and K. Bisher, A demographic overview of the current and projected library workforce and the impact of federal funding, Library Trends 59(1,2) (2010), 6-29.

[6] J.G. Marshall and V.R. Neufeld, A randomized trial of librarian educational participation in clinical settings, J. Med. Educ. 56(5) (1981), 409-416.

[7] J.G. Marshall, The impact of the hospital library on clinical decision making: The Rochester study, Bull. Med. Libr. Assoc. 80(2) (1992), 169-178.

[8] J.G. Marshall et al., Towards a shared approach to alumni career tracking: Results from the workforce issues in library and information science 2 study, Library Trends 59(1,2) (2010), 30-42.

[9] J.G. Marshall et al., The value of library and information services in patient care: Results of a multi-site study, J. Med. Libr. Assoc. 101(1) (2013), 38-46.

[10] J.G. Marshall et al., Where are they now? Results of a career survey of library and information science graduates, Library Trends 58(2) (2009), 141-154.

[11] Workforce Issues in Library and Information Science, Part 1. Theme issue that contains 13 articles on WILIS and several other workforce studies, Library Trends 58(2) (2009), 320 pp.

[12] Workforce Issues in Library and Information Science, Part 2. Theme issue that contains 19 articles on a wide variety of workforce studies, Library Trends 59(1,2) (2010), 380 pp. 